\title{
Determinants of technical efficiency in the Zimbabwean manufacturing industries
}

\author{
Simon Munongo ${ }^{1}$, Shallone. K. Chitungo ${ }^{1}$ \\ ${ }^{1}$ Great Zimbabwe University \\ Box 1235 Masvingo, Zimbabwe
}

\begin{abstract}
This study investigates the determinants efficiency of manufacturing subsectors in the Zimbabwean economy. The study applied the panel data econometrics approach in the leading manufacturing subsectors from 1980-2005. The technical efficiency estimates using SFA shows that there are varying efficiencies across subsectors and through time.

The log-likelihood test shows that there existed technical inefficiency in the production processes in the manufacturing sector. This shows that the industries could improve their productive capacities with the same amount of inputs.

The study shows that in the Zimbabwean manufacturing industries between 1980 and 2005 industries with strong the human capital development and foreign direct investment flows had higher efficiency. The concentration of foreign owned firms in an industry and capital intensity had no effect on the efficiency of an industry.
\end{abstract}

Keywords: efficiency, frontier, technical and stochastic

\section{INTRODUCTION}

Modern industrial organization is concerned about boosting the productive capacities of economies; this has become an important policy issue in developing nations (Timmer, 1971). Therefore, the need to improve the effective and efficient use of resources is important especially in the manufacturing sector which is central to the industrialization process of nations. The efficiencies vary across industries and through time within the same industry (Abuka, 2002). In this regard, we wish to measure the technical efficiency in the Zimbabwean manufacturing industries and give an analysis of the variations in the inefficiencies across industries and through time, using the stochastic frontier approach (SFA). An underlying production function is used to measure technical efficiency scores for the manufacturing industries.

Technical efficiency is used to define the ability of a firm to get maximum output given a set of inputs levels (Coelli, 2000). It is closely intertwined with allocative efficiency which refers to the ability of an industry to use the inputs in optimal proportions given their respective prices. These measures combined give total economic efficiency. This is used to measure economic performance of the industries measured by the divergences of the input-output relation from the best attainable levels (Howard, 2003) Little attention has been given to technical efficiency in the Zimbabwean manufacturing industries yet this is an important factor in determining the competitiveness of the manufacturing sector in the international world and has great implications on welfare gains. Previous studies on resource utilization in the Zimbabwean manufacturing sector focused on specific periods using the Data Envelopment Approach (DEA). One such study by Bjurek and Durevall (2000) focused on changes in total factor productivity due to the Economic Structural Adjustment Programme (ESAP) (1991-1996).

This study seeks to exploit the use of panel data econometrics to establish the technical efficiency scores and the determinants of technical efficiency since 1980-2005 in the manufacturing sector. This study contributes to the Zimbabwean economy in determining the technical efficiency of industries at a sub sector level and the sector level heterogeneity on technical efficiency is determined. Thus this study seeks to show efficiency variations using rich panel data econometric techniques to show 
productivity loss due to technical inefficiency from twelve Zimbabwean manufacturing sub-sectors.

A study on the determinants of technical efficiency in the manufacturing industries in the period 19802005 will enable us to give an analysis on the effect of recently introduced policies in the manufacturing industries.

\section{THE ZIMBABWEAN MANUFACTURING SECTOR}

The Zimbabwean manufacturing sector is defined as the mechanical or chemical transformation of materials into new products ${ }^{1}$. The assembly of component parts of manufactured products is considered as manufacturing except in cases where activity is more appropriately classified as construction. Establishments primarily engaged in repair works for industry or commerce is classified as manufacturing depending on the type of product to be repaired. This section will give an account of the manufacturing sector and the leading subsectors in our study.

\section{OVERVIEW OF THE MANUFACTURING SECTOR}

Zimbabwean economy was on the growing trend since the pre-colonial period to the early 1990 s, with a significant rise from $3.1 \%$ in 1956 to $10.3 \%$ in 1991 (CSO, 2001). However, the GDP growth went on a negative slump in the 1990s with $-5.7 \%$ output declines in 1992 and $-1.5 \%$ in 2000 following a series of financial and economic crises. Zimbabwe is one of the African economies with a more diversified and integrated economy that experienced considerable growth in the 1980s, with an average growth of 3.3\% between 1981 and 1991 (World Bank, 1995). However, the reforms that were adopted in the1990s and the recurrent droughts in the same period led to the negative growth rates with an average of $-1.5 \%$ from 1991 to 1997 . From 2000 the economy was on a free fall with a $-10.5 \%$ fall in 2000 and in 2001 there was a further fall of $19.0 \%$ following the recent economic and financial crises (CSO, 2003).

${ }^{1}$ CSO definition 1989
The manufacturing sector in Zimbabwe used to be the leading sector in the economic growth of the country from 1980 to 2001 as shown on the table below

Table 1 Structure of the Zimbabwean economy as \% of GDP 1981-2001

\begin{tabular}{|l|l|l|l|l|}
\hline & 1981 & 1991 & 2000 & 2001 \\
\hline Agriculture & 17.5 & 15.3 & 18.5 & 17.6 \\
\hline Mining & 31.3 & 37.4 & 25 & 24.5 \\
\hline Manufacturing & 21.5 & 27.2 & 15.8 & 13.9 \\
\hline Services & 5.1 & 47.3 & 56.5 & 57.1 \\
\hline
\end{tabular}

****adopted from World Bank Report 2001

Zimbabwe had one of the largest and fastest growing manufacturing sectors in Africa in the 1980s to 1990s. In 1939 it accounted for $10 \%$ of GDP and $7 \%$ of paid workforce by the end of the 1980 s it rose to $26 \%$ of GDP and $16 \%$ of paid workforce with half the total exports (Riddell 1990a 339). Zimbabwe inherited a highly industrialized economy in 1980 at independence from Britain; the manufacturing sector contributed $25 \%$ of the GDP, and produced 7000 different products (Bjurek et al 2000).

As shown in table 1 above the manufacturing sector had a significant share of the sectoral contribution to the GDP. In the 1980s the manufacturing sector was the leading sector in the economy though it was overtaken by the services sector in the 1990s. The Zimbabwean economy relies heavily on agricultural production. For example in 1981 agriculture contributed $17.5 \%$ to GDP, industry accounted for $31.3 \%$ and manufacturing accounted $21.5 \%$ with services contributing only $5.1 \%$ as shown in the table above.

The manufacturing sector had no competition before ESAP in the 1980s due to government protectionist policies. The policies included price controls, foreign exchange rationing, constrained access to imports of machinery, spare parts and raw materials. Thus, there was low capacity utilization hence the liberalization of the 1990s and trade reforms should have impacted positively on technical efficiency, firm establishment and competition (CZI, 2000) The major government policy after independence was growth with equity aimed at eliminating previous economic and social imbalances 
along racial divide (government report I998).

The dominance of the manufacturing sector in the Zimbabwean economy has been felt throughout the production history of the economy to date and the sector was on a rising trend since the preindependence period. However, this trend fell as the whole economy started to decline in the face of the failure of ESAP to stimulate economic growth. Thus the manufacturing share to GDP fell to 20.9 $\%$ of GDP in 1993 and suffered a further decline to $17.4 \%$ in 2000 (CZI, 2000). Other sectors had lower contributions to GDP than the manufacturing contribution with the following agriculture contributing $17.6 \%$ in 1987 and overtaking manufacturing in 2000 contributing $18.4 \%$ (see Bjurek et al 2000).

The manufacturing sector growth in Zimbabwe can also be attributed to the investment in capital which was on the rising trend throughout the period 19851997 with a rise of $14.8 \%$ in 1985 to $30.6 \%$ in 2000 (CSO 2001). However, investment in the manufacturing sector as a proportion of GDP has fallen sharply in recent years from 23\% in 1996 to current levels of 12\% (CZI, 2003). Manufacturing investment as a proportion of total investment has fallen from $41 \%$ in 1996 to a level below $18 \%$ in the period 2002 to 2005 (CZI, 2006). This trend is attributed to poor economic growth and foreign currency shortages which hamper the introduction of new machines and new materials which reduce people were employed and was on a steep growth in the late 1980s. There was a significant decline in the manufacturing employment in the early 1990s due to the negative effects of ESAP. This led to massive industrial retrenchments across all sectors of the economy due to lack of competitiveness in the face of massive competition from foreign firms following government's liberalization policies. Employment increased from 1995 to 1997 before going on a free fall up to recent years following the economic crises that started in the late 1990s.

Manufacturing employment has been on a downward spiral since 1999. In 1998 there was a modest growth of $5 \%$ before the sector registered negative growth rates in $1999,2000,2001$ and the first six months of 2003 (CZI, 2003), where job losses of $3.5 \%, 9.6 \%, 1.5 \%$ and $5.4 \%$ were posted in the sector and the sector shed about 39000 workers. manufacturing competitiveness. Thus, the companies cannot embrace the information technology revolution and manufacturing has been lagging behind due to external competition on local and external markets.

The growth in manufacturing production fell at the end of the 1990s with a decline of $4.4 \%$ in 1999 and a further decline of $11.5 \%$ in 2000 . The most affected sectors being textiles, wood and furniture and food with declines of $16 \%, 18 \%$ and $12.8 \%$, respectively (CSO, 2000). The manufacturing output then went on a free fall since1997 to 2005 owing to the economic recession that hit the nation. The fall in the output is attributed to shortages of basic commodities fuel, electricity, local and foreign currency (CZI, 2003).

The Zimbabwean economy has been on a continuous decline between 2000 and 2005 due to both exogenous and internal factors (CZI, 2006). On the exogenous frontier drought conditions that afflicted the Southern African region over the period 2001 to 2003, also had a negative bearing on manufacturing output. On the internal front the macroeconomic instability affected output.

According to a CZI survey (2003) the capacity utilization in the manufacturing sector was $60 \%$ in 2002 , with $30 \%$ in the-sample showing excess capacity of around $30 \%$.

In 1985 an average of 163461

The manufacturing sector recorded marginal growth in value addition between 1980 and 1995 moving from US\$1248 million in 1980 to US\$1260 million in 1995 an average of $0.006 \%$ growth rate per annum (CZI, 1999).

\section{STOCHASTIC PRODUCTION MODELS}

The stochastic frontier model was first suggested by Aigner et al (1977). In their study they proposed the use of decomposed error term associated with frontiers which included the traditional random error term and a new one-sided inefficiency measure component in order to overcome the 
weaknesses of the deterministic approach ${ }^{2}$. Their model was defined as:

$\gamma_{i}=\chi_{i} \beta+\left(v_{i}-\mu_{i}\right)$.

In this model, the random error term $v_{i}$, takes note of the measurement error and other factors and is independently and identically distributed with mean zero and constant variance. The $\mu_{i}$ that accounts for the technical efficiency is independent of the $v_{i}$.

Early empirical literature used cross-sectional data. Pitt and Lee (1981) were the first to widen the model to panel data approach. Their method has an advantage of giving an analysis of both technical change and technical efficiency change over time. The model is defined as:

$\gamma_{i t}=\chi_{i t} \beta+\left(v_{i t}-\mu_{i t}\right) \ldots \ldots \ldots$

Where $\chi, \beta, v, \mu$ and $\gamma$ are defined in equation above and there is an introduction of time t.

Early studies using this approach assumed that technical inefficiency effects are time invariant. This approach with the assumption of time invariant technical inefficiency did not fully utilize the advantages of using panel data where individual industry in efficiencies can be estimated for several years ${ }^{3}$.

Battese and Coelli (1992) proposed the model:

$$
\begin{aligned}
& \gamma_{i t}=\chi_{i t} \beta+\left(v_{i t}-\mu_{i t}\right) \ldots \ldots . . \\
& i=1 \ldots \ldots . N, t=1 \ldots \ldots . . T
\end{aligned}
$$

Where $\gamma_{i t}$ is the $\log$ of production in the $i$-th industry in the $t$-th time $\chi_{i t}$ is a vector of inputs quantities of the $i$-th industry at time $t$ and $\beta$ is a vector of unknown parameters. The error term is

\footnotetext{
${ }^{2}$ The only difference between the two models was the assumption of the distribution of the one-sided error term Meesen and van der Broeck assumed an exponential distribution to $\mu$ whereas Aigner et al used both half and exponential distribution.

3 As Coelli, Rao and Battese (1998) point out the pattern of technical efficiency effects can change over time.
}

composed of two parts; $v_{i t}$ is assumed to be independent and identically distributed as $N\left(0, \delta^{2}\right)$ and independent from $\mu_{i t}$. The $\mu_{i t} \mathrm{~s}$ are defined by Battese and Coelli (1992) as:

$$
\mu_{i t}=\exp (-\eta(t-T)) \mu_{i}
$$

The $\mu_{i t} \mathrm{~s}$ are non-negative random variables, which are assumed to be the measure of technical efficiency in production and are to be identically and independently distributed as truncations of zero of the $N\left(0, \delta^{2}\right)$ distribution, where $\eta$ is a parameter to be estimated, which determines if the inefficiencies are time varying or time invariant.

Battese and Coelli (1995) extended their model so that it included the estimation of parameters believed to influence the technical efficiency level of producers and applied the approach of panel data.

The stochastic frontier approach involves fitting stochastic production or cost frontier models to data. The model has a virtue that it does not attribute all deviations from the frontier to inefficiency unlike DEA which combines stochastic noise with efficiency thus the stochastic frontier produces more reliable results. It also allows statistical hypothesis testing regarding the nature and magnitude of inefficiency.

The stochastic frontier approach however suffers some shortcomings that firstly it requires explicit functional form for the production technology for example Cobb Douglas. Secondly it assumes a functional form in the distribution of inefficiency measures.

\section{APPLICATION OF THE SFA TO MANUFACTURING INDUSTRIES}

Since the path breaking article on efficiency by Aigner, Lovell and Schmidt (1977) and Meeusen and van den Broeck (1977) which introduced the stochastic frontier model to estimate technical efficiency in manufacturing industries the method has received much attention and has been extended to other sectors for example agriculture and financial sectors. 
The importance of technical efficiency on economic performance started to be an issue of interest to economists in Africa as early as 1980s, in a study on the effects of efficiency on economic performance using evidence from Ghana Page Jr (1980). The model used in this study was the stochastic frontier model. The study concluded that technical efficiency affect measured economic performance.

In Indonesia technical efficiency measures using stochastic frontier were also introduced in the 1980 after a study by Pitt and Lee (1981) where they used pooled data in the weaving industries for the years 1972; 1973 and 1975. Based on time variant and time invariant stochastic frontier analyses their estimates of average efficiency ranged between $60 \%$ and $70 \%$ in the garment industry. This study was mainly constrained by the use of crosssectional data which requires strong distributional assumptions on the independence of the efficiency measures and the regressors, than the panel data estimates which has more desirable statistical estimates.

Tybout (1998) used the SFA in a study for Taiwanese industries and reports the majority of industries had technical efficiency gains under trade liberalization periods experiences an increase in the skill labour intensity of production. He also concluded that an increase in industry technological sophistication is a result of increased foreign competition.

Panel stochastic frontier functions were also extended to cross country studies by Collier et al (1998) in a study to test the impact of exporting on firm level efficiency using data from Kenya, Zimbabwe, Ghana and Cameroon from 1992-1995. They concluded that exporting firms increase their efficiency more rapidly than non exporting companies and also found that new entrant exporting firms gain more efficiency than existing firms. The study only captured an analysis of only four sectors for Zimbabwe, food, metal, textiles and wood. This reduced the effectiveness of the study in policy formulation for the manufacturing sector thus the need for a country specific study A country specific study was done by Lundvall and Battesse (1998) using an unbalanced panel of 235 Kenyan manufacturing firms in the food, wood, textile and metal sectors. They utilized the stochastic frontier approach to measure technical efficiency. They also inquired the impact of firm size and age on efficiency and concluded that firm age is directly related to efficiency.

Ugur (2000) used the stochastic frontier in the Irish manufacturing sector. The paper measured the technical efficiency levels in the Electrical and Optical Equipment industry. Using the model outlined by Battese and Coelli (1995) they concluded that export intensity is not important in explaining technical efficiency in the manufacturing industries. Their results are not very useful in policy formulation since they used a few sectors and cannot be used to explain the efficiency in the whole manufacturing sector.

\section{Methodology}

Stochastic frontiers have been used to measure efficiencies in the manufacturing industries since they were independently coined by Aigner et al (1977) and Meeusen and van den Broeck (1977). A production frontier represents the maximum amount of output that can be produced given a set of inputs. Since most firms typically fall below this output, the deviation from the maximum output is the measure of inefficiency and is the focus of our empirical work.

This study is going to employ the stochastic frontier approach in context of panel data. The advantage of panel data inefficiency measures is that it separates industry specific effects that are not related to inefficiency (Battese et al 2000). The stochastic production approach that we will employ takes the form:

$Q_{i t}=f\left(X_{i t}, \beta, t\right)+\varepsilon_{i t} \ldots \ldots \ldots \ldots \ldots \ldots .(1)$

$Q_{i t}$ is the gross output for the i-th industry in year $t, X_{i t}$ is a vector of input variables and $\beta$ is a vector of unknown parameters to be estimated and $f$ (.) denotes the Cobb Douglas function. Green (1993) indicates that in the stochastic model it is the disturbance term which is the focal point of analysis rather than the catch-all for the unknown factors omitted from the regression.

Our model, combines two stochastic elements in the error term, that is $\varepsilon_{i t}=v_{i t}-\mu_{i t}$ The 
conventional symmetric error term $v_{i t}$ is assumed to be independent and identically distributed as $N\left(0, \delta^{2}\right)$ and it captures the variation in output that result from factors that are beyond the control of the industry such as labour market conflicts, measurement pathologies in the .dependent variable and excluded explanatory variables of the production function. The remainder component of the error term is the disturbance $\mu_{i t}$ which captures industry- specific technical inefficiency in production.

We employ the stochastic frontier method suggested by Kumbhakar (1990) in the panel data context in which technical inefficiencies effects vary systematically with time in time varying specifications ${ }^{4}$. This has an advantage of differentiating technical inefficiencies from technical change.

According to Coelli (1996), technical efficiency of the individual industry is defined in terms of the ratio of observed output to the corresponding frontier output, conditional on the level of inputs used in the industry. Technical efficiency of industry $i$ at time $t$ in the stochastic frontier production function equals the ratio of observed output to estimated frontier output:

$T E_{i t}=\frac{Q_{i t}}{\exp \left(f\left(X_{i t}, \beta, t\right)\right)}=\exp \left(-\mu_{i t}\right) \ldots . .2$

Since $\mu_{i t}$ is defined as non-negative random variable, the technical efficiencies will lie between zero and unity, where unity indicates that a firm is technically efficient.

\section{ECONOMETRIC SPECIFICATION}

Stochastic frontier production estimation is most preferred since it deals with the weakness of the

${ }^{4}$ This is because managers learn from previous experience in the production process and so their technical inefficiency would change in some persistent pattern over time (Coelli, Rao and Battese) non-frontier methodology assumptions that all industries are fully realizing their capacity in the production process and are thus efficient (Mahadevan 2000).

The model specification for this study follows the leads of Tybout (1991), Tybout and Westbrook (1991), Hadad (1993) and Harrison (1990) in the use of a Cobb Douglas specification at industry level. The choice of the Cobb Douglas specification is based on two reasons: Firstly, because industrial census data is more likely to support a simple functional form (Grileches and Ringstand 1971), secondly Cobb Douglas specification allows maximum flexibility in dealing with data imperfections (Tybout n1991). We will employ a generalized Cobb Douglas function that accommodates more than two inputs and has no restrictions on parameters.

The model specification will be of form:

$$
\begin{aligned}
& \operatorname{In} Q_{i t}=\operatorname{In} A+\beta_{1} \operatorname{InL}_{i t}+\beta_{2} \operatorname{In} K_{i t}+ \\
& \beta_{3} \operatorname{In}_{i t}+\beta_{T} t+v_{i t}-\mu_{i t} \ldots \ldots \ldots \ldots . .3
\end{aligned}
$$

Where $Q_{i t}$ is the gross output of industry i at time $t$

A is the average level of productive efficiency in the industry

$\mathrm{L}_{\mathrm{it}}$ is the labour measured as the number of people employed in industry $i$ in year $t$

$\mathrm{K}_{\mathrm{it}}$ is the capital stock in industry $i$ in year $t$

$\mathrm{M}_{\mathrm{it}}$ is the intermediate materials in industry $i$ at time $t$ in the production process

$\beta_{1}, \beta_{2}$ and $\beta_{3}$ are the scalars for which the sum represents the returns to scale

$\beta_{T}$ is a measure for time effects in the production process

$v_{i t}$ is the stochastic error term that shows measurement error

$\mu_{i t}$ captures the individual inefficiency measure

\section{DATA AND SAMPLE CHARACTERISTICS}

The data for this study covers twelve manufacturing industries in the Zimbabwean economy classified under the four digit 
International Standard Industrial Classification (ISIC). The data includes gross output, average number of people employed; capital stock is calculated using the simple perpetual inventory method and the intermediate materials. The study relies on secondary data published by the central statistical office on industrial production censuses since 1980 and CZI reports. We are going to use gross output in each sub-sector as our dependent variable is the observed outputs

\section{a) Gross output $(Q)$}

The dependent variable is gross output which is the turnover plus the value of capital repairs undertaken by the industry's own employees, adjusted for change in the value of stocks of own produced goods. This gives the measure of observed output since it encompasses all the production activity in the industry. The variable was obtained from the CSO census of industrial production and CZI, reports.

\section{b) Labour $(L)$}

The production function has labour as one of the independent variables. We measure this as the average number employed, includes all the people on the pay roll whether employed full time or part time. Owners and their members of family are also included if they are on the payroll and are paid a definite wage or salary. The average is calculated from the number employed at the end of each month of the financial year. This gives the average of the labour force that contributed to the gross output produced at the end of the year. The variable is obtained from the CSO censuses of industrial production.

\section{c) $\operatorname{Capital}(K)$}

The other input to the production function is capital which is the true capital stock, following Ahluwalia (1991) and Harrison (1994). The gross capital stock estimates at constant prices are derived using the perpetual inventory method. The method assumes that the capital stock measure was available for at least one year. This requires data on the gross capital stock for the benchmark year and the gross investment for all the years. It is calculated as:

$$
K_{t}=K E_{t}+K_{t-1}
$$

where $\mathrm{K}_{\mathrm{t}}$ is the capital stock in period $t, K E_{t}$ is the total capital expenditure in period $t$ and $\mathrm{K}_{\mathrm{t}-1}$ is the capital stock from the previous period $t-1$. This give the total capital stock used to produce an output in a period and we assume away depreciation.

\section{d) Materials $(M)$}

The final variable in the production inputs is the intermediate goods. This measures all the materials used by an industry in the production in a financial year. This is a sum of the electricity and water, fuel and other intermediate products measured in monetary value.

\section{TECHNICAL EFFICIENCY IN THE ZIMBABWEAN MANUFACTURING INDUSTRIES}

The descriptive statistics of the technical efficiency estimates areshown in table 6 shows that the average technical efficiency is 0.66 . Therefore, on average the manufacturing sector industries can improve their output by 34 percent with the same set of inputs. The statistics also show great differences in the efficiency levels in the sector with a maximum efficiency level of 99 percent, and the minimum is 14 percent.

Table 6: Summary statistics of efficiency

\begin{tabular}{|l|l|l|l|l|l|}
\hline Variable & Obser. & Mean & $\begin{array}{l}\text { Std.dev } \\
.\end{array}$ & Min & Max \\
\hline Efficiency & 312 & 0.659 & 0.238 & 0.138 & 0.991 \\
\hline
\end{tabular}

The results reveal that the canning, preservation of fruit and vegetables is the most efficient industry and the average efficiency in the sector is 98.3 percent. The highest efficiency in the industry was 99.1 percent in 1980 and the fell slightly as the years progressed to 97.4 percent in 2005 . The high efficiency in the sector is attributed to the growth in the agricultural sector in the 1990s and increase in local firms in the sector since 1980 which enhanced competition and efficiency. The sector is also constituted with many small firms which are more efficient and effective in capacity utilization hence its leading position in the technical efficiency The lowest efficient sub-sectors are the footwear and textile sectors, the footwear industry were on average 33 percent efficient. Thus, reallocation on 
input resources in this sector can improve production significantly. The inefficiency of the footwear industry can be attributed to the hegemony of Cold Storage Commission in the industry which was a parastatal before its privatization in 1997 . This probably reinforces the general understanding that parastatals are inherently inefficient. According to Mead and Kanyetu (1992) the footwear had two players Bata and Superior this constrained the competition in the industry and thus inefficiency.

The textiles sector is 32 percent efficient. The sector was affected by a huge growth in employment that increased by 65\% since 1984 . Thus, the textiles sector was affected by diseconomies of scale thus high levels of resource underutilization. The sub-sector is also dominated by large companies that are slow in increasing efficiency over time.

Bakery production had a maximum efficiency of 69.5 percent and the rrurumum efficiency in the sub- sector was 34.1 percent. The sub-sector on average 52.9 percent efficient and hence can increase output by 47.1 percent without changing input quantities. The moderately high efficiency estimates in the sub-sector can be attributed to a well developed education system in the baking profession hence qualified workers improved efficiency.

The sawmilling and wooden product except furniture sub sector is the second leading efficient industry. The average efficiency in this sub sector is 95 percent. The high efficiency averages in the sub-sector is due to the exposure of the industry to international competition since it is a high exporting industry. There is also high capital investment in the sub-sector and hence improved efficiency.

The third most efficient sub sector is the beer, wine and other alcoholic beverages sector which is 92 percent efficient. The high efficiency in the beer, wine and other alcoholic beverages sector may be attributed to the competition in the sector given the number of foreign imported brand in the market and also there were development of various brands in the economy since 1980 .

Most of the sub-sectors in the study were on average more than 50 percent efficient which indicates that manufacturing industries have been generally performing well since 1980 . The tobacco processing sub-sector had and average of 65.5 percent efficient. The efficiency level in the tobacco industry is explained by the structure of the sub-sector which is dominated by foreign owned industries which are efficient and effective in resource utilization.

Metal products are on average 54.8 percent efficient. Relatively low efficiency in the metal industry is due to the dominance of ZISCO, a parastatal which is always rocked by corruption and abuse of profits that hamper efficiency. Printing and publishing sub sector has 82.7 percent efficient on average. The high efficiency in the printing industry is due to the high skilled labor in the sub-sector. Chemical products are 72.9 percent. High efficiency in the chemicals sub-sector is due to international exposure of the as it compete vigorously in the sub-Saharan Africa region.

Rubber industry is 67.7 percent efficient on average. The sub sector though dominated by a few players, there is competition that encourages efficient resource utilization.

The sub-sectors thus show varying efficiency level; appendix 1 shows that textiles and footwear had the least average efficiency levels; these sectors had little foreign competition even during the trade liberalization period. Canning, printing and publishing, beer and wood industries had the highest averages which are over 80 percent.

The average annual efficiency estimates show that the efficiency in the manufacturing industries has been on a free fall since 1980 . There are a number of possible reasons behind the fall in the efficiencies such as lack of competition in the economy due to government protective policies since independence. Although the government tried liberalization policies in the early 1990s most manufacturing subsectors did not gain in efficiency since they were pushed out of the market due to foreign competition

The average efficiency estimates were on a more rapid fall since 2000 due to the recent economic recession in the Zimbabwean economy that has lead to scaling down of most industries. The fall in average efficiency is due to underutilization of industrial plants and also the closure of most industries in most sub-sectors has reduced the 
competition in the manufacturing industries which reduced efficiency substantially.

\section{CONCLUSIONS \& POLICY RECOMMENDATIONS}

Our study of the efficiency variations in the Zimbabwean manufacturing industries was structured as follows. The second chapter gave an analysis of the performance of the manufacturing sector throughout history; it also gave a sub sector by sub sector performance analysis. Chapter three looked at the foundations of the efficiency measurement and various other studies that applied the stochastic frontier approach in the study of technical efficiencies in the manufacturing sectors. The third chapter gave an account of the two main measures of efficiency the DEA and the stochastic frontier. The method of measurement and the steps in the quantitative approach in our study is out lined in the fourth chapter. The results of the study are in the fifth chapter. Having come such a long way we now want to take a close look at our findings with a view to make conclusions and policy recommendations for the benefit of industrialists and government policy makers.

\section{FINDINGS AND POLICY IMPLICATIONS}

The aim of this study was to give a measure of the level of inefficiency that exists in the manufacturing sector. Given the log likelihood test the study concludes that there exist inefficiency effects in the Zimbabwean manufacturing industries hence there is urgent need to improve management skills to enhance efficient use of manufacturing resources.

The mean efficiency is 0.659 which indicates that on average an industry is 34.1 percent inefficient. Thus there can be an increase in the output without increasing the inputs by 34.1 percent. The minimum efficiency is 0.135 and is in the textiles industry and the highest efficient industry operates at 99.1 percent efficiency and is the cannmg and preservation of vegetables and fruits industry. This shows a huge difference in the resource use and thus government incentives need to be spread unevenly to help the least efficient industries to increase efficient utilization of resources and improve the national output.

Generally, the industrialists need to device better management skills and in some extent change management to enhance better use of resources in the manufacturing industries in Zimbabwe.

\section{REFERENCES}

[1] Abuka C.A (2005), Efficiency and technical change in South African manufacturing. University of Pretoria South Africa.

[2] Aigner and Chu (1968), On estimating the industry production function, American Economic Review 58:4 (September) 826-39.

[3] Aigner, D.J., Lovell, C.A.K., and Schmidt, P.J. (1977). Formulation and estimation of stochastic frontier production function models. Journal of Econometrics 6(1): 21-37.

[4] Battese G.E and T.J Coelli (1992), Frontier production function, technical efficiency and panel data, with application to poultry farmers in India. Journal of Productivity Analysis, 3: 15369.

[5] Bjurek H and Durevall D (2000). Does market liberalization increase total factor productivity? Evidence from manufacturing sector in Zimbabwe, Journal of Southern African Studies Vol 26.

[6] C.Z.I (1999). Manufacturing sector overview.

[7] C.Z.I (2000). Manufacturing sector review.

[8] C.Z.I (2007).Manufacturing sector results analysis, Survey June 2007.

[9] Coelli T.J (2000). Data Envelopment Approach software, Department of Econometrics, University of New England Arm dale NSW, 2351, Australia.

[10] Collier P(1998). Export and firm-level efficiency in the African Manufacturing Sector, World Bank, Washington D.

[11] CSO (2001). National Accounting Report. 
[12] CSO (2003). Census of Industrial production.

[13] Government Report (1998).

[14] Howard (2003), Efficiency in trucks on road construction, An evaluation of DEA.

[15] Kumbhakar S.C (1990), Production frontier, panel data and time-varying technical efficiency. Journal of Econometrics. 46. pp 201-212.

[16] Mahadevan (2000). How technically efficient are Singapore's manufacturing industries? Applied Economics number 32 pages 2007-2014.

[17] Marcos (2000). Technical efficiency in the Spanish manufacturing industries: a panel data approach, Applied Economics 32 page 1249-1258.

[18] Martin, J.P., Page Jr., J., (1980). The impact of subsidies on X-efficiency in LDC industry: theory andan empirical test. Review of Economics and Statistics 65, 608- 617.

[19] Meeusen, Wand Van den Broeck, J., (1977). 'Efficiency Estimation from Cobb- DouglasProduction Functions with
Composed Error' in International Economic Review.VoI18, pp 435-444.

[20] Pitt, M. M., and L. F. Lee, 1981, The measurement of sources of technical efficiency in the Indonesian weaving industry, Journal of Development Economics, 9, pp. 43-64. pp 21-37.

[21] Schmidt, P. (1976) "On the Statistical Estimation of Parametric Frontier Production Functions" Review of Economics and Statistics 58:2 (May), 238-39.

[22] Timmer c.p (1971). 'Using a probabilistic Frontier Production Function to measure Technical Efficiency', Journal of political economy 79:4 July/August 776-9.

[23] Tybout (1998). Effects of liberalization on efficiency: A case for Taiwan, Journal of Econometrica Vol 23 page 22.

[24] Ugur (2000). Efficiency in Irish manufacturing sector. Trinity College Dublin. UNDP report (2004).

[25] World Bank Report (1995). Global Development finance, Washington. 


\section{APPENDIX 1 EFFICIENCY ESTIMATES}

year industry bakery tobacco Textiles footwear metal printing 19800.6951590 .7870650 .5128440 .5222680 .7096640 .899143 19810.6840320 .7787620 .4978470 .5074060 .6989480 .894942 19820.6726040 .7701860 .4826520 .4923370 .6879310 .890579 19830.6608740 .7613340 .4672780 .4770760 .6766120 .88605 19840.6488440 .75220 .4517450 .4616440 .6649920 .881348 19850.6365160 .7427820 .4360740 .446060 .6530730 .876468 19860.6238950 .7330760 .4202890 .4303470 .6408550 .871406 19870.6109830 .7230780 .4044130 .4145280 .6283420 .866156 19880.5977860 .7127880 .3884750 .3986290 .6155380 .860712 19890.5843120 .7022020 .37250 .3826760 .6024480 .85507 19900.5705680 .6913190 .3565180 .3666980 .5890790 .849224 19910.5565630 .680140 .3405610 .3507240 .5754370 .843169 19920.5423080 .6686640 .3246590 .3347860 .5615320 .8369 19930.5278160 .6568930 .3088450 .3189150 .5473740 .830411 19940.5130980 .6448280 .2931540 .3031440 .5329750 .823698 19950.4981720 .6324730 .2776180 .2875080 .5183460 .816756 19960.4830520 .6198310 .2622740 .2720410 .5035040 .809579 19970.4677580 .6069070 .2471560 .2567780 .4884640 .802164 19980.452310 .5937080 .23230 .2417540 .4732430 .794506 19990.4367270 .5802410 .2177390 .2270030 .4578610 .786601 20000.4210340 .5665140 .2035090 .2125620 .4423390 .778445 20010.4052560 .5525370 .1896420 .1984620 .4266980 .770035 20020.3894170 .5383220 .1761710 .1847380 .4109640 .761367 20030.3735450 .5238810 .1631260 .1714210 .395160 .752439 20040.3576690 .5092290 .1505350 .158540 .3793150 .743248 20050.341820 .494380 .1384260 .1461230 .3634560 .733793 
year industry wood chemicals Beer Canning plastics rubber 19800.9695870 .8371750 .9518140 .9910090 .6133410 .815515 19810.9682690 .8306230 .9497490 .9906120 .6001680 .808188 19820.9668950 .8238380 .9475990 .9901980 .5867140 .800609 19830.9654630 .8168140 .9453610 .9897660 .5729850 .792774 19840.9639720 .8095470 .9430320 .9893150 .5589920 .784676 19850.9624180 .802030 .9406080 .9888450 .5447430 .776311 19860.9607990 .7942590 .9380860 .9883540 .5302520 .767674 19870.9591130 .7862290 .9354630 .9878410 .5155310 .758762 19880.9573570 .7779350 .9327340 .9873060 .5005960 .749569 19890.9555290 .7693710 .9298960 .9867480 .4854610 .740093 19900.9536260 .7605350 .9269460 .9861660 .4701460 .730331 19910.9516440 .7514230 .9238790 .9855590 .4546690 .720279 19920.9495820 .742030 .9206920 .9849250 .4390530 .709936 19930.9474360 .7323540 .9173810 .9842640 .4233190 .699301 19940.9452020 .7223930 .9139410 .9835740 .4074930 .688372 19950.9428790 .7121440 .9103680 .9828550 .3915990 .67715 19960.9404630 .7016060 .9066580 .9821050 .3756660 .665635 19970.937950 .6907780 .9028080 .9813230 .3597220 .653829 19980.9353370 .6796610 .8988120 .9805070 .3437970 .641734 19990.932620 .6682550 .8946660 .9796560 .3279230 .629354 20000.9297970 .6565620 .8903660 .9787680 .3121310 .616692 20010.9268630 .6445830 .8859080 .9778430 .2964560 .603755 20020.9238150 .6323230 .8812860 .9768790 .2809310 .590549 20030.920650 .6197860 .8764980 .9758730 .2655910 .577081 20040.9173630 .6069780 .8715380 .9748250 .250470 .563362 20050.913950 .5939040 .8664020 .9737330 .2356030 .549401 Source: FRONTIER 41 Regression output from data obtained from the Central Statistical Office 